\begin{tabular}{|c|c|}
\hline $\begin{array}{c}\text { ÇÜTAD } \\
\text { Çukurova Üniversitesi } \\
\text { Türkoloji Araștırmaları Dergisi }\end{array}$ & $\begin{array}{c}\text { Cilt 6, Sayı } 1 \\
\text { Haziran } 2021\end{array}$ \\
\hline $\begin{array}{l}\text { ISSN: 2587-1900 } \\
\text { E-ISSN: 2548-0979 }\end{array}$ & $\begin{array}{l}\text { Geliş Tarihi: } 07.04 .2021 \\
\text { Kabul Tarihi: } 31.05 .2021\end{array}$ \\
\hline \multicolumn{2}{|c|}{$\begin{array}{l}\text { Makale Künyesi (Araştırma): Mengi, N. (2021). Sait Faik'in yalnızlı̆̆ } \\
\text { Öyle Bir Hikâye. Çukurova Üniversitesi Türkoloji Araştırmaları Dergisi } \\
6(1), 335-344 \text {. }\end{array}$} \\
\hline \multicolumn{2}{|c|}{ https://doi.org/10.32321/cutad.911400 } \\
\hline
\end{tabular}

\title{
SAİT FAİK'İN YALNIZLIĞI: ÖYLE BİR HİKÂYE
}

\section{Nesrin MENGí $\dot{I}^{1}$}

\section{ÖZET}

“Öyle Bir Hikâye”, gerçeküstü unsurların gerçeklikle iç içe oluşuyla okuyucuda farklı bir etki yaratırken aynı zamanda edebiyatta sıkça işlenen yol öykülerinden biridir. Anlatıcı, kendi yalnızlığını gidermek için aynı toplumsal kesimden seçilmiş figürlerin olduğu öyküler üretir. Sait Faik'in yalnızlığı belli bir insanın yaşadığı, aşksızlıktan ya da kimsesizlikten kaynaklanan bir yalnızlıktan çok modern kent yaşamının birey üzerindeki yalnızlaştırıcı etkisidir. Onun bütün öykülerinde olduğu gibi "Öyle Bir Hikâye" öyküsünde de insan sevgisi esastır; ancak, sevginin varlığı insanın yalnızlığını ortadan kaldırmaya her zaman yeterli olamaz. Bu öyküde "yeterli olmama" durumunun modernizmin sonucu olduğunu fark eden bir yazar tavrıyla karşıslaşılır.

Burada Sait Faik'in yeni biçimler denediği Alemdăg'da Var Bir Yllan kitabındaki öykülerden biri olan "Öyle Bir Hikâye" öyküsü, biçim özellikleri ve "yalnızlık" izleğinin işlenişindeki özgün tavır bakımından değerlendirilecektir.

Anahtar kelimeler: Öykü, yalnızlık, gerçeküstü.

\section{THE LONELINESS OF SAITT FAIKK: ÖYLE BİR HİKÂYE}

\begin{abstract}
"Öyle Bir Hikâye" creates a different effect on the reader by the intertwining of surreal elements with reality. It is also one of the frequently handled road stories in literature. The narrator produces stories in which figures selected from the same social segment in order to dispel her loneliness. The loneliness of "Sait Faik" is the isolating effect of modern urban life on the individual rather than a
\end{abstract}

\footnotetext{
${ }^{1}$ Mersin Üniversitesi, Fen Edebiyat Fakültesi, Türk Dili ve Edebiyatı Bölümü, Doç. Dr.ncanbek@mersin.edu.tr https://orcid.org/0000-0002-7834-9347
} 


ÇÜTAD
Haziran 2021

loneliness caused by lovelessness or desolation where a certain person lives. As in all of his stories, human love is essential in the story "Öyle Bir Hikâye"; However, the presence of love is not always sufficient to eliminate man's loneliness. In this story, an attitude of the writer is encountered who realizes that "not being enough" is the result of modernism.

Here, the story of "Öyle Bir Hikay", one of the stories in the book "Alemdağ'da Var Bir Y1lan" in which "Sait Faik" tried new forms, will be evaluated in terms of its stylistic features and the original attitude in the processing of the "loneliness" theme.

Keywords: Story, loneliness, surreal.

\section{GİRIŞ}

Cumhuriyet dönemi yazarlarından Sait Faik Abasıyanık (19061954), edebiyat yaşamı boyunca öykü, roman, şiir, deneme gibi türlerde eser vermekle birlikte, öykücü kimliğiyle öne çıkar. Sait Faik öyküsü, olaya dayanmayan yapısıyla var olan öykü kurallarını dışlarken samimi bir duyarlıkla ele aldığı insan gerçeğini farklı inceliklerle dile getirir.

“Öyle Bir Hikâye”, yazarın sağlığında, son dönem öykülerinin bir arada olduğu ve 1954'te yayımlanan Alemdağ'da Var Bir Yılan adlı kitabında yer alır. Kitap; "Öyle Bir Hikâye", "Alemdağ'da Var Bir Yılan", "Yalnızlığın Yarattı̆̆ı İnsan", "Panco'nun Rüyası" dışında "Yani Usta", "Kafa ve Şişe", "Çarşıya İnemem", "Hişt, Hişt!..", "Dülger Balığının Ölümü”, "Yılan Uykusu" gibi öykülerin de içinde olduğu toplam on altı öyküden oluşur. $\mathrm{Bu}$ kitaptaki öyküler, gerçeküstü yaklaşımlara ve sembolik anlatımlara dayalı biçim özellikleriyle Türk öykücülügünde “çığır açmış”tır.

Selim İleri, Türk öykücülügünde Sait Faik'in "boyuna gencelen bir yazar olduğunu” söyler (İleri, 1975, s. 17). Sait Faik, Sabahattin Ali'yle birlikte kendilerinden sonra gelen öykücüleri etkilemişlerdir. Birçok genç öykücü kendi öykü anlayışlarını bu iki yazara bakarak belirlemeye çalışmıştır. Sabahattin Ali, Ömer Seyfettin, Refik Halit, Yakup Kadri gibi yazarların oluşturduğu memleket gerçekliği çizgisi ile sonra gelen yeni arayışlar arasında sağlam bir köprü kurar. Sait Faik ise, 1934'te Varlık dergisinde yayımlamaya başladığı öykülerinde sıradan insanın sorunlarını, mutluluklarını, yoksunluklarını, yaşam sevinçlerini anlatırken klasik öykü kalıplarının ve anlayışının değiştirilmesine öncülük eder (Gümüş, 2001, s. 46-74). Başka bir ifadeyle Sait Faik, öykünün yapısında ve içerikte gerçekleştirdiği yeniliklerle, öncesindeki edebiyat geleneğiyle ilişkisiz olduğu ve birinci kişi anlatıcının anlatma isteğiyle biçimlendiği 
hissedilen özgün öykücülük anlayışıyla, öykünün yazınsal bir tür olarak önem kazanmasında büyük bir rol oynar (Dirlikyapan, 2007, s. 64). Özellikle 1950 kuşağı öykücülerinin çoğu, Alemdağ'da Var Bir Yllan kitabının, o yıllarda öykücülükte yaşanan yeniliklerin başlatıcısı olduğu konusunda ortak düşünceye sahiptir. Örneğin, dönemin öykü yazarları arasında yer alan Demir Özlü, Yeni Ufuklar dergisinin 1967 yılında hazırladığı bir soruşturmada Sait Faik'in Alemdağ'da Var Bir Yılan adlı kitabıyla kalıplaşmış rasyoneli yıktığını, kendilerine duyuşun, bireyliğin ve yaratmanın yollarını açtığını ifade eder (Özlü, 1967, s. 67). Ferit Edgü ise 1950 kuşağıyla Sait Faik arasında ilişki kurarken 'Dostoyevski'nin, 'Hepimiz Gogol’ün Palto'sundan geliyoruz' dediği gibi, ben de, benim kuşağımın öykü yazarlarının büyük bir çoğunluğu da, Sait Faik'ten geliyoruz.” (Edgü, 2003, s. 27) sözleriyle Sait Faik öykücülüğünün kuşağın inşasındaki yerini belirginleştirir:

Bizler, öngördüğümüz, özlediğimiz, duyumsadığımız ama tam olarak ne menem bir şey olacağını kestiremediğimiz yeniliğin tohumlarını, Alemdağ'daki öykülerde buluvermiştik. Alemdağ'da Var Bir Yılan'la birlikte, sanki önümüz açılmıştı. Sait Faik, bu öyküleriyle, o dönemin Türk yazınındaki yalınkat ya da güdümlü gerçekçilik anlayışına sırtını dönüyor ve bizlere yeni bir yol öneriyordu. Etik ve estetik değerler; toplumsal ve bireysel gerçeklik birbirini zedelemeden, tam tersine, birbirinden güç alarak var olabilirlerdi” (Edgü, 2003, s. 27).

Alemdăg'da Var Bir Yılan, yazarın 1951 yılında yayımlanan Havuz Başı ile başlayan değişim sürecinin son aşamasıdır. Başka bir ifadeyle, Alemdağ'da Var Bir Yılan kitabı hem onun öykücülüğünün zirvesi hem de Türk öykü dünyasında büyük bir yeniliktir. Çehov tarzını sürdüren, hatta onu aşan öyküler barındırır. Sait Faik buradaki öykülerle o güne kadar süregelen öykü realitesinin "çanlarını bozmuş"tur.

$\mathrm{Bu}$ yenilik ve değişimleri șu șekilde sıralamak mümkündür: "Hikâyenin merkezine yazarın bir birey olarak kendini ve kendisiyle ilgili sorunları yerleştirerek, anlatıcı-yazar-hikâye kişisi arasındaki mesafenin kaldırılması", "hikâyede gerçeküstü olay ve durumlara yer verilmesi”, "olay merkezli hikâyeden uzaklaşılarak hikâyenin; duygular ve izlenimler etrafinda kurulması", "toplumsal temalardan uzaklaşılarak bireyin varoluşu, yalnızlık, ölüm ve umutsuzluk temalarının ele alınması", "serbest çağrışımlarla gelişen bir anlatım dilinin oluşturulması", "hikâyenin anlatımının alegori ve imgelerle örülü bir dille kurulması", "dil kullanımında yapısal ve anlamsal sapmalara yer verilmesi” ve "farklı hikâyeler arasında ortak motifler aracılığıyla metinlerarası ilişkilerin kurulması.”(Kurt, 2011, s. 1466). 
“Öyle Bir Hikâye”, “Alemdağ'da Var Bir Yılan”, "Yalnızlığın Yarattığı İnsan" ve "Panco'nun Rüyası" öyküleri birbiriyle bağlantılıdır. "Ancak bu bağlantı, bir olay bütünlüğ̈̈ sağlamaktan çok, 'ben' anlatıcının kentin sokaklarında gezinirken yaşadıklarının ve gerçeklik düzeyinde belirsiz sınırlara sahip olan 'Panco'yla kurduğu 'hayalî-gerçek' ilişkinin öykülere yayılmasıyla ifadesini bulur." (Dirlikyapan, 2007, s. 69).

\section{BİÇIME DAİR BİRKAÇ SÖZ VE "YALNIZLIK" İZLEĞİ}

"Öyle Bir Hikâye", gerçeküstü unsurların gerçeklikle iç içe oluşuyla okuyucuda farklı bir etki yaratırken aynı zamanda edebiyatta sıkça işlenen yol öykülerinden biridir ve karşılaşmaları içerir. Öyküde adı verilmeyen anlatıcı, kendi yalnızlığını gidermek için aynı toplumsal kesimden seçilmiş figürlerin yer aldığı öyküler üretir.

Yağmurlu bir gecede sinemadan çıkan anlatıcı bir dolmuşa atlar, Şişli'den Atikali'ye gelir. Atikali'ye neden geldiğini bilmediğimiz anlatıcı sokakta yürümeye başlar. Dostu Panco'nun rüyasında futbol oyunları gördüğünden, pişpirik oynadığından söz ederken bir süre sonra "Panco rüya da görmüyor, demincek attım" (Abasıyanık, 2011, s. 9) diyerek üstkurmaca tekniğini kullanır. Anlatıcı yürümeye sürdürürken evin birinden bir adam firlar ve hiç tanımadığı anlatıcıya "Dostumu öldürdüm abi! Sakla beni" (Abasıyanık, 2011, s. 9) diye seslenir. Anlatıc1, Hidayet adındaki bu yabanciya hemen cebine girmesini söyler ve o da cebe girip kaybolur. Anlatıcının Hidayet'in cebine girmesini istemesi okuyucuda beklenmedik bir etki yaratır. Yazarın amacı okuyucuyu metne yabancılaştırmaktır. Hidayet, dostu Pakize'yi neden öldürdüğünü anlattığı sırada birisinin gelmesiyle paltonun cebinde bir susam tanesi gibi büzülür. Anlatıcı, geri kalan kısmı kendisinin uyduracağını söyleyerek Hidayet'in susmasını ister. Hidayet bu kez pire olur ve "Fatih Camii avlusunun çitlembik ağacının dibine doğru" (Abasıyanık, 2011, s. 11) firlayıp gider. Anlatıcı, Hidayet'in öyküsünü Panco'ya anlatmak için "uydurmaya" başlar ve bu yeni öyküyü tamamladığında kendisini rahatlamış hisseder. "Bir oh çektim. Rahatlamıştım. Keyiflenmiştim. Panco domuzuna bir hikâye anlatacaktım.” (Abasıyanık, 2011, s. 11).

Anlatıcı bir süre sonra Fatih parkında, 1slak yerde oturan bir adamla karşılaşır ve onun yaşama sevincine dair düşündüklerini dinler. Adam konuşmasını bitirdiğinde, o da tıpkı Hidayet gibi, anlatıcıdan kendisini "Panco'ya anlatmasını ister. Sanki herkes Panco'ya-bir anlamda okura-anlatılacak hikâyeleri yaratmak ve anlatıcı da-tıpkı Sait Faik gibi-bu öyküleri derlemek için sokaklardadır." (Dirlikyapan, 2007, s. 70). 
Ardından anlatıcı köprüde sarhoş, genç bir zamparaya rastlar. Genç adam ona çok içtiğini söylediğinde, "İçmeli delikanlı, içince çok içmeli" der. Genç, anlatıcıya "sen de çok mu içerdin?" diye sorduğunda nasıl bir tavır takındığını anlatırken "Alt dudağımı üst dudağıma adamakıllı yapıştırıp sağ elimle de havaya hafiften iki-üç tokat salladım. Panco, sen de yap böyle, ne demek istediğimi anlarsın." (Abasıanık, 2011, s. 17) sözleriyle seslenilen kişi birdenbire değişir ve Panco olur. Ancak Panco'nun tek bir kişiyi temsil ettiğini ya da yalnızca hayalî bir arkadaş olduğunu düşünmek doğru olmaz. Nitekim, okur da anlatıcının söylediği hareketi yaparak onun demek istediğini anlamaya çalışacaktır. Dolayısıyla tek boyutta ele alınamayacak olan Panco, Sait Faik'in sokaklarda gezinerek anlatacak öyküler aradığı okur olarak da düşünülebilir (Dirlikyapan, 2007, s. 70). Kaldı ki, anlatıcı öykünün en başından itibaren her firsatta Panco'ya seslenir. Her duyduğu öyküyü Panco'ya anlatacağını tekrarlayıp durur. Her karşılaşmada yeni bir öykünün izini sürerken Panco'ya sesini duyurmak ister. Panco'yla iletişim kurmak için onun mahallesine gider. "Panco hep kabahat sende. Sen ettin bu işi bana. Gece yarısı senin hesabına dolaşıyorum. Sen ettin bu işi." (Abasiyanık, 2011, s. 16).

Sait Faik, özellikle son dönem öykülerinde akıl ve sıra dışı olanı kurgusal gerçekliğin bir parçası hâline getirir. Anlatıcının her şeyden önce Panco gibi hayalî bir muhatap üretmesi onun metinlerindeki yeni bir gerçekliğin habercisidir. Bu hayalî muhatap kimi zaman okurun yerine konulurken kimi zaman da Sait Faik'in ikinci bir kimliği gibi görünür. Bu ikinci kimlik, Sait Faik'e/anlatıcıya kendi durumunu gösteren bir ayna gibidir (Kurt, 2011, s. 1470).

Sait Faik, öykülerinde kendini saklamayan bir yazardır (Uyguner, 1968, s. 237). Kurmaca ve otobiyografinin iç içe geçtiği, aradaki sınırların kalktığı bir öyküdür "Öyle Bir Hikâye". Yazar, yalnızca otobiyografiye ait özellikleri değil, başka türlere ait biçim özelliklerini de öyküye taşır. Bunları öyküye dâhil ederek türün olanaklarını genişletir. Örneğin, denemeye yaklaşan, okurla sohbet eden, "müdahil yazar tavrıyla adeta okurla birlikte öyküyü kurgulamıştır." (Tosun, 2013, s. 61).

Yukarıda da ifade edildiği gibi, bu öykü edebiyatta işlenen yol öykülerinden biridir. Bir edebî metinde yazar, eğer kahramanı dışarı çıkartıyorsa öykünün kahramanı mutlaka birileriyle karşılaşır ve bu karşılaşmalar aynı zamanda temayı oluşturur. Burada da asıl öykü, anlatıcının gece sinemadan sonra bindiği dolmuştan inip yürümesiyle başlar. Gece gezintisi sırasında önce sevgilisini öldüren Hidayet'le, sonrasında parkta oturan yaşlı adamla, köpekle ve çapkın arabacıyla 
karşılaşır. Gecenin sonunda anlatıcı Panco'nun evine kadar gelir. Öyküyü dikkat çekici kılan özellik, anlatıcının tesadüfen bir araya geldiği insanlar, onlarla olan ilişkisi ve bu karşılaşmalarda ortaya çıkan üst gerçekliktir.

$\mathrm{Bu}$ öyküde güvenilmez bir anlatıcı tipolojisi söz konusudur. Başka bir ifadeyle, okura oyunlar kuran, onu şaşırtmaya çalışan bir anlatıcı vardır. Öykü, "Sinemadan çıktığım zaman yağmur yine başlamıştı. Ne yapacağım? Küfrettim. Ana avrat küfrettim. Canım bir yürümek istiyordu ki...” (Abasıyanık, 2011, s. 8) cümleleriyle başlar. "Sinemadan çıktığım zaman yağmur yine başlamıştı." cümlesindeki "yine” ifadesi ya da "Ne yapacağım?" sorusu daha önceden okurla Panco’yla- başlayan bir sohbetin devam ettiğinin göstergesi gibidir. Okur, daha öncesinde de yağmurun yağdığından haberdardır. Devamında "Gider miyim Atikali'ye gecenin bu saatinde, giderim. Atladım şoförün yanına. Dere tepe düz gittik. Otomobilin buğulu, damlalı camlarında kırmızı, sarı, yeşil, türlü ışıklar görerek, bir renk dalgası içinde Atikali'ye vardık." (Abasıyanık, 2011, s. 8) bölümündeki "Dere tepe düz gittik" cümlesi bir masal kalıbıdır ve öyküde bilinen kalıpların dışına çıkılacağını sezdirir. Bir başka yerde, "İşte bu minval üzre Panco geldim sizin mahalleye, yağmur yine başladı. Tam sizin evin önünde bir küp kırılmış, yarısı paramparça, yarısı sapasağlam. Küpün içine oturdum. Başladım anlatmaya Atikalipaşa'ya bir gece yarısı nasıl gittiğimi, Hidayet'in cebime nasıl girdiğini, Fatih parkında yatan adamı, sokak köpeğini ve Yahudi karısının arabacı zamparasını. Sen uyuyordun." (Abasıyanık, 2011, s. 19) derken yine, bir masal ögesi olan "küp” evin önünde kırılmış, üstelik anlatıcı küpün içine oturmuştur. Dolayısıyla öykünün ilk cümlesinden başlayarak bizi şaşırtan bir anlatıcıyla karşılaşırız. Anlatıcı Hidayet'i tanımazken, Hidayet Panco'yu tanımaktadır. Burada olup bitenler gerçekliğe aykırı bir durumdur ve anlatıcıya olan güveni sarsar. Ancak öykü ilerledikçe "Bu öyküde her şey mümkündür, olmayacak şey yoktur." düşüncesi egemen olmaya başlar. Böylesi bir durum, öykü dünyasındaki gerçekliğin ne kadar değişken olabileceğini gösterir; anlatıcı, Hidayet anlatmasa da Hidayet'in öyküsünün devamını getirir. Karşılaştığı adamın yanına oturduğu yeri sslak ve soğuk olduğu halde rahat bulur ya da gece vakti gökyüzünden sarışın sarışın, esmer esmer bulutlar geçer, kibrit konuşur ve yağmura rağmen yanmaya devam eder. "Fatih parkının demirine dayalı uyuyan adam" da Panco'yu tanır ve anlatıcının Faik Bey'in oğlu olduğunu bilir. Dolayısıyla Sait Faik, insan aklının sapmalarını, bilinç akışını öyküye aktarır. Bilinçli, kontrollü bir anlatıcıdan söz etmek güçleşir: 


CÜTAD
Haziran 2021

Hidayet Pakize'nin ta kalbine bir vurușta kocaman bir çivi saplamıştı. Başka çaresi yoktu. Susam helvaları yiyen çocuklar, kadınlar Hidayet'ten bu hikâyeyi beklemezlerdi. Susam helvası karın doyurmazdi. Pakize susam helvacıya da varamam a, demişti. Seviyormuş... Sevgi karın doyurur mu? Hidayet o akşam süslenmiş, Taksim'e çıkmıştı. On sekiz lira otuz yedi kuruş parası vardı. Bir meyhaneye girdi içti de içti. İçtikçe Hidayet'e koydu. Artık minareye baktığı zaman minarenin aleminin göğe doğru yükselişini Pakize ilen bir bulutsuz ay mehtaplı gecede seyretmeyecekti, demek. Hırkaişerif e bu yol mu gider diye bir kadıncağız sorduğu zaman Hidayet kafasının içinde, sarı yün kazağı altında kaybolmuş, Pakize'ye aynı suali sorup da: "Bu yol mu gider, öteki mi, ben ne bileyim Fatma Hanım!" derse, o da kadıncağızın şaşırmış yüzüne gülümseyerek aynı şeyleri söyleyemeyecekti, ha.

Başını tüyler gibi, kediler gibi, temiz tülbentler ve mendiller gibi kokan Pakize'nin dizlerine hiç mi hiç koyamayacaktı.

Ulan bu çiviyi de kim koymuştu cebine. O piç Abdullah yok mu? O canım çocuk. O çilli, esmer yüzlü, badik burunlu, Karakaplan kulübü santrhafı canım oğlan Abdullah. O koymuş olacaktı çiviyi. Yarım sinema bileti, yarım stadyum bileti, diş firçası, İngiliz anahtarı, bozuk yale kilidi, ispermeçet mumu, çiklet, kurtlu kiraz, sabun, karpuz kavun çekirdeği, soğan sarmısak koyan piç kurusu çiviyi ne bok yemeye kor. Kocaman temel enserisi. Pırıl pırıl da. Biz gibi de ince... Panco'ya hazırda hikâye (Abasıyanık, 2011, s. 11-12).

Sait Faik'in neredeyse her öyküsünde "yanıltıcı kabuğu biraz kazıyınca altta özü, asıl şekli" buluruz. Hangi seviyeden, hangi meslekten olursa olsun, başlangıçta duygu yoksunluğu gibi bir izlenim bırakan öykü kahramanı birden bire bir halk filozofu, bir şair, bir düşünür olarak kabuğunu dışarı vurur ve oradan itibaren öykünün etkisi genişler. Onun öykülerinde kahraman ya kendini aşmak için çırpınır ya da bir süre için başka türlü anlaşılmaya müsait kimliğini gerçek çizgileriyle ifşa eder (Necatigil, 1954, s. 8). Örneğin, parkta oturan adamın yaşama sevinci üzerine söyledikleri ya da anlatıcının köpeğe ahlak üzerine verdiği küçük "konferans", metnin bütünlüğü içinde fazlalık gibi dursa da, Sait Faik toplumda gözlemlediği kimi meseleler üzerine düşündüklerini bu yolla öyküye taşır:

Baktım, Zeyrek yokuşunun seddi dibinde uyumuş bir köpek. Yanına oturdum. Gözünü açtı. Böcül böcül baktı. Korka korka kafasını okşadım. Gözünü yumdu. Bir konferans da ben ona çektim. Dedim ki:

Oğlum patlak göz. Ben insanoğlu. Sen hayvanoğlu. Bundan milyonlarca sene evvel her ikimiz de kurttuk, solucandık, tek hücreli mahluktuk. Ondan evvel boşlukta bir tozduk. Sonra bak işte bu hale geldik. Bundan sonra belki böyle kalırız. Belki değişiriz. Ama böyle kalmayalım. Siz de bedbahtsınız, biz de. Evlerde uyuyanlar, ipekler 


ÇÜTAD
Haziran 2021

içinde uyuyanlar, kadın koynunda uyuyanlar, soba başında kıvrılmış bobiler de var. Lastikten kemikleri, topları var. Hanımları atar, koşup getirirler. Sabahları kapıcılar gezmeye çıkarırlar. İnsanlar var, sevdiklerini almışlar şu saatte koyunlarına, dalmışlar iki kişilik rüyalarına. Pekâlâ ne yapalım? Ama sen Zeyrek yokuşunda kuyruksuz, tüysüz, uyuz, soğuktan titreyen bir sokak köpeği, ben Panco'nun arkadaşı, başka hiçbir şey değil, yağmura vurmuş, uykusuz, canı burnunda, yüreği Ağaççileği sokağında, kafası Bomonti tramvay durağından yüz metre uzakta kirli bir yastıkta bir adamcağızım. Ne yapalım? Günün birinde dostluklardan, insanlardan ve hayvanlardan ve ağaçlardan ve kuşlardan ve çimenlerden yapılmış vazife hissi ile çarpan yüreklerle dolu bir âlemde yaşıyacağımızı düşünelim. Bir ahlakımız olacak ki hiçbir kitap daha yazmadı. Bir ahlakımız, bugün yaptıklarımıza, yapacaklarımıza, düşündüklerimize, düşüneceklerimize hayretler içinde bakan bir ahlakımız. O zaman seninle daha uzun dostluklar ederiz patlak göz. O zaman hiç merak etme. Dostum Panco da bana hak verecektir. Kilise ahlakından söz açmayacak. Dostluğun olağanüstü güzelliğini çocuklarına anlatacaktır (Abasıyanı, 2011, s. 16-17).

Yazar, köpeğe sınıfsal farklılığı anlatır. Sokak köpeği ve zengin ev köpeğinin yaşam koşullarındaki farklılıkları dile getirir ve insanları da onlara benzetir. Sait Faik tavrını sokaktakinden yana koyar. O, her zaman insandan yanadır; cebinde adam saklar, parktaki yaşlı adamın derdini dinler, sarhoş arabacının kusmuğunu temizler. Hiyerarşik bir yapıyı benimsemez, bu insanlarla konuşurken kendi konumunu ortaya koymaz:

Atatürk Köprüsü'nde rastladım adama. İki elini tırabzana dayamış, Haliç'e öğürüyordu. Yanında durdum. Zıplar gibi iki üç defa daha ayakkabılarının ucuna basarak yükseldi. Sonra durdu. Mendilimi çıkarıp gidip yüzünü sildim. Ağzını sildim. Gözüne düşen saçlarını elimle taradım. Yüzünü bana çevirince iki büyük ve siyah göz dostça bakt1.

- Çok içtim amca, dedi.

Ukalalık etmedim.

- İçmeli delikanlı, dedim, içince çok içmeli.

- Aşkolsun amca, dedi, sen de bizdenmişsin.

- Zamanında, dedim (Abasıyanık, 2011, s. 17).

Yazar küçük insanı anlatırken kimi zaman var olan düzene eleştirel bir tavır sergiler. Ancak bu eleştirileri bir teklife dönüşmez. Yalnızca tespit eder, okura ideolojik bir düşünceyi dayatmaz. "Çünkü onun peşinde olduğu, adı konmuş toplumsal bir proje yoktur. İnsanların hayallerinin gerçek olduğu, herkesin mutlu olduğu, haksızlıkların olmadığı özgür bir dünyayı arzuladığını vurgulamakla 
birlikte, bu beklentilerini bir siyasi hareketle irtibatlandırmaz." (Tosun, 2013, s. 62).

"Öyle Bir Hikâye" bir yalnızlık öyküsüdür. Adaların birinde annesi ve köpeğiyle birlikte yaşayan anlatıcı kendini yalnız hisseder ve biriyle konuşmaya ihtiyaç duyar. Çevresiyle iletişim kuramayan, dışlanmış insanları seçer. Anlatıcı sesini arkadaşı Panco'ya duyurmak ister; ancak, aralarındaki iletişimsizlik yüzünden bunu başaramaz:

Sen uyuyordun.

- Hey Panco, Panco, seslendim.

Sesim bir pencereyi deldi. Gitti senin kulağını buldu. Uyandın. Ama artık benim sana kadar yetiştirecek ne sesim, ne halim kalmıştı. Sen de tekrar uykuya daldın. Bir otomobil geçiyordu. - Bomonti’ye gidiyor musun ă̆abey, dedim.

- Atla, dedi.

Atladım (Abasıyanık, 2011, s. 19).

\section{SONUÇ}

Gerçeküstü unsurlarla anlatılan karşılaşmalardaki kişiler ve köpek yalnızlığın yarattığı figürlerdir. Anlatıcı yalnızlığından kurtulmak için öyküler oluşturur. Sait Faik'in yalnızlığı, belli bir insanın yaşadığı, aşksızlıktan ya da kimsesizlikten kaynaklanan bir yalnızlık değildir. $\mathrm{O}$, modern kent yaşamının birey üzerindeki yalnızlaștırıcı etkisini öyküleştirir. Onun bütün öykülerinde olduğu gibi, "Öyle Bir Hikâye"de de insan sevgisi esastır; ancak, -her șey bir insanı sevmekle başlasa da- sevginin varlığı insanın yalnızlığını ortadan kaldırmaya her zaman yeterli olamaz. Bu öyküde iletişimsizlikten kaynaklanan "yeterli olmama" durumunun modernizmin sonucu olduğunu fark eden bir yazar tavrı vardır. Buradaki yalnızlık hâli, daha çok bireysel yalnızlıktır. İçe kapanma şeklinde görünür ve temelinde kurulamayan iletişim vardır. Bu hâl, kimi zaman bilinçli bir oluşumken kimi zaman da toplumun tutumundan kaynaklanır. $\mathrm{Bu}$ duruma toplumun yalnızlaştırıcı etkisi denilebilir.

Sait Faik, insanın yalnızlığından, yabancılaşmasından, sevgisizlikten, eşitsizlikten bahsederken bilinen öykü kalıplarına bağlı kalmaz. Onun öyküsü, Türk şiirinden önce gerçeküstüyü keşfeder. Gerçeğin başka türlü, gerçeküstü bir anlatımla da yansıtılabileceğini gösterir. "Öyle Bir Hikâye" anılan bu özellikleri barındıran öykülerden biridir. 


ÇÜTAD
Haziran 2021

\section{KAYNAKÇA}

Abasıyanık, S. F. (2011). Alemdağ'da var bir yılan (13. bs.). İstanbul: Yapı Kredi Yayınları.

Dirlikyapan, Ö. J. (2007). Yazınsal kavrayışta köklü bir değişim: Türk öykücülügünde 1950 kuşağl. Yayımlanmamış doktora tezi, Ankara: Bilkent Üniversitesi Ekonomi ve Sosyal Bilimler Enstitüsü.

Edgü, F. (1997). Öyküde 1950 kuşağı. Düşler-Öyküler, 3, 27-28.

Fethi Naci. (2003). Sait Faik'in hikâyeciliği. İstanbul: Yap1 Kredi Yayınları.

Gümüş, S. (2001). Öykücülüğümüzün kısa tarihi. Çağdaş Türk Yazını 42-62 (Zehra İpşiroğlu, Haz.), İstanbul: Adam Yayınları.

İleri, S. (1975). Türk öykücülügünün genel çizgileri. Türk Dili Türk Öykücülüğ̈̈ Özel Sayısı, 286, 2-29.

Kurt, M. (2011). Modernizm ve gerçeküstülük bağlamında Sait Faik'in son hikâyeleri. Turkish Studies International Periodical For the Languages, Literature and History of Turkish or Turkic, 6(3), 1463-1475.

Necatigil, B. (1954). Sait Faik'in kahramanlarında kılık ve ruh. Varlık, 413, 7-8.

Özlü, D. (1967). Demir Özlü'nün yanıtı. Yeni Ufuklar Özel Sayl: 1950-1960 Kuşağının Ozan ve Hikâyecileri Kendi Kendileriyle Hesaplaşıyorlar, 176, 66-71.

Tosun, N. (2013). Sait Faik: Hayata, yalnızlığa, avareliğe övgü. Öykümüzün kırk kapısı, Ankara: Hece Yayınları, 61-68.

Uyguner, M. (1968). Yapıtlarına göre Sait Faik’te vücut yapısı. Varlık, 717, 11. 